\title{
Single Domain 3C-SiC Growth on Off-Oriented 4H-SiC Substrates
}

\author{
Valdas Jokubavicius, Gholam Reza Yazdi, Rickard Liljedahl, Ivan Gueorguiev Ivanov, \\ Jianwu Sun, Xinyu Liu, Schuh Philipp, Martin Wilhelm, Peter Wellmann, Rositsa Yakimova \\ and Mikael Syväjärvi
}

\section{Linköping University Post Print}

\section{Tweet}

N.B.: When citing this work, cite the original article.

Original Publication:

Valdas Jokubavicius, Gholam Reza Yazdi, Rickard Liljedahl, Ivan Gueorguiev Ivanov, Jianwu Sun, Xinyu Liu, Schuh Philipp, Martin Wilhelm, Peter Wellmann, Rositsa Yakimova and Mikael Syväjärvi, Single Domain 3C-SiC Growth on Off-Oriented 4H-SiC Substrates, 2015, Crystal Growth \& Design, (15), 6, 2940-2947.

http://dx.doi.org/10.1021/acs.cgd.5b00368

Copyright: American Chemical Society http://pubs.acs.org/

Postprint available at: Linköping University Electronic Press http://urn.kb.se/resolve?urn=urn:nbn:se:liu:diva-118525 


\section{Single domain 3C-SiC growth on off-oriented $4 \mathrm{H}-\mathrm{SiC}$ substrates}

Valdas Jokubavicius*, ${ }^{1}$, G. Reza Yazdi ${ }^{1}$, Rickard Liljedahl ${ }^{1}$, Ivan G. Ivanov ${ }^{1}$, Jianwu Sun ${ }^{1}$, Xinyu Liu ${ }^{1}$, Philipp Schuh ${ }^{2}$, Martin Wilhelm², Peter Wellmann², Rositsa Yakimova ${ }^{1}$, Mikael Syväjärvi ${ }^{1}$

${ }^{1}$ Department of Physics, Chemistry and Biology (IFM), Semiconductor Materials Division, Linköping University, 58183 Linköping, Sweden

${ }^{2}$ Materials Department 6 (i-meet), Crystal Growth Lab, University of Erlangen, Martens Straße 7, D91058 Erlangen, Germany

ABSTRACT We investigated the formation of structural defects in thick $(\sim 1 \mathrm{~mm})$ 3C-SiC layers grown on off-oriented $4 \mathrm{H}-\mathrm{SiC}$ substrates via lateral enlargement mechanism using different growth conditions. A two-step growth process based on this technique was developed, which provides a trade-off between the growth rate and the number of defects in the 3C-SiC layers. Moreover, we demonstrated that the twostep growth process combined with geometrically controlled lateral enlargement mechanism allows formation of single 3C-SiC domain which enlarges and completely covers the substrate surface. High crystalline quality of the grown $3 \mathrm{C}$-SiC layers is confirmed using high resolution $\mathrm{x}$-ray diffraction and low temperature photoluminescence measurements.

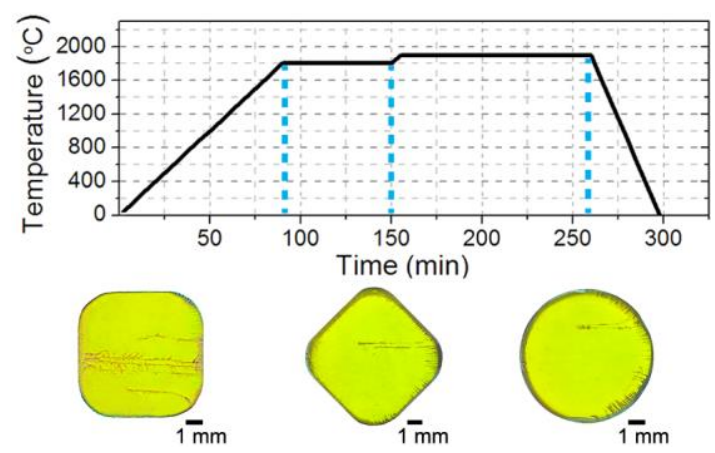

Figure. Free standing 3C-SiC and a schematic illustration of the two-stage growth process

\footnotetext{
*Valdas Jokubavicius

Department of Physics, Chemistry and Biology (IFM), Semiconductor Materials Division, Linköping University, 58183 Linköping, Sweden

Phone: +4613282641

Email: valjo@ifm.liu.se
} 


\title{
Single domain 3C-SiC growth on off-oriented $4 \mathrm{H}-$
}

\section{SiC substrates}

Valdas Jokubavicius ${ }^{*}$, , Gholam R. Yazdi ${ }^{1}$, Rickard Liljedahl ${ }^{1}$, Ivan G. Ivanov ${ }^{1}$, Jianwu Sun ${ }^{1}$, Xinyu Liu ${ }^{1}$, Philipp Schuh ${ }^{2}$, Martin Wilhelm ${ }^{2}$, Peter Wellmann ${ }^{2}$, Rositsa Yakimova ${ }^{1}$ and Mikael Syväjärvi ${ }^{l}$

${ }^{1}$ Department of Physics, Chemistry and Biology (IFM), Semiconductor Materials Division, Linköping University, 58183 Linköping, Sweden

${ }^{2}$ Materials Department 6 (i-meet), Crystal Growth Lab, University of Erlangen, Martensstr. 7, D91058 Erlangen, Germany

KEYWORDS: 3C-SiC, lateral enlargement, sublimation epitaxy, geometrical control

\begin{abstract}
We investigated the formation of structural defects in thick $(\sim 1 \mathrm{~mm}) 3 \mathrm{C}-\mathrm{SiC}$ layers grown on off-oriented $4 \mathrm{H}-\mathrm{SiC}$ substrates via lateral enlargement mechanism using different growth conditions. A two-step growth process based on this technique was developed, which provides a trade-off between the growth rate and the number of defects in the 3C-SiC layers. Moreover, we
\end{abstract}


demonstrated that the two-step growth process combined with geometrically controlled lateral enlargement mechanism allows formation of single 3C-SiC domain which enlarges and completely covers the substrate surface. High crystalline quality of the grown $3 \mathrm{C}$-SiC layers is confirmed using high resolution x-ray diffraction and low temperature photoluminescence measurements.

\section{INTRODUCTION}

The great challenge to obtain high crystalline quality cubic silicon carbide (3C-SiC) has hampered its use in semiconductor applications. ${ }^{1-4}$ In order to accelerate the $3 \mathrm{C}$-SiC application in electronics high quality thick $3 \mathrm{C}-\mathrm{SiC}$ layers or substrates are needed. They could be used for homoepitaxial growth, e.g., by chemical vapor deposition (CVD) which allows reproducible growth of device quality 3C-SiC layers. In addition, thick layers could be explored as seeds in bulk growth techniques like seeded sublimation growth to obtain large 3C-SiC crystals/boules. However, thick layers of $3 \mathrm{C}-\mathrm{SiC}$ with quality similar to that in commercially available hexagonal (4H- and $6 \mathrm{H}) \mathrm{SiC}$ substrates have not been demonstrated.

There are fundamental challenges in the growth of single crystal 3C-SiC. Heteroepitaxial layers of 3C-SiC grown on silicon substrates contain high density of structural defects due to a large mismatch in lattice parameter $(\sim 20 \%)$ and thermal expansion coefficient $(\sim 8 \%)$. In contrast, the mismatch problems are substantially smaller when using hexagonal SiC substrates

(in-plane lattice mismatch $\sim 0.08 \%$ for $3 \mathrm{C} / 4 \mathrm{H}) .{ }^{5}$ However, despite promising results, ${ }^{6-9}$ the control of initial nucleation of $3 \mathrm{C}-\mathrm{SiC}$ domains on hexagonal $\mathrm{SiC}$, especially when growing on 
nominally on-axis substrates, and the reproducibility of high crystalline quality layers, in particular thick ones, remain problematic.

Recently, a generic concept of producing 3C-SiC layers with substantially less number of domains, compared to the $3 \mathrm{C}-\mathrm{SiC}$ grown on nominally on-axis substrates, has been demonstrated using a lateral enlargement (LE) mechanism on off-oriented hexagonal SiC substrates. ${ }^{10}$ The LE mechanism allows to localize the initial nucleation of 3C-SiC domains on an in situ formed large terrace with an on-axis area at the edge of hexagonal substrate. These domains enlarges along the step-flow [11-20] direction and completely cover the surface. It was shown that a reproducible growth of 3C-SiC layers without foreign polytype inclusions can be obtained using this approach. However, even though substantially reduced in number, the layers still contain incoherent twin boundaries, also called double positioning boundaries (DPBs), which have a

pronounced influence on electrical characteristics ${ }^{11,12}$ and thus have to be eliminated in order to unleash the full potential of $3 \mathrm{C}-\mathrm{SiC}$ for various applications.

In this paper we present a two-step process combined with a geometrically controlled LE mechanism that leads to the growth of single domain 3C-SiC layers. Such 3C-SiC growth approach has been developed on the ground of detailed analysis of the formation of various structural defects in 3C-SiC layers grown under different growth conditions and different growth arrangements. In addition, we demonstrate that $3 \mathrm{C}-\mathrm{SiC}$ layers with profound thickness $(>1 \mathrm{~mm})$ can be grown and used to obtain free-standing $3 \mathrm{C}-\mathrm{SiC}$ substrates.

\section{EXPERIMENTAL DETAILS}

The 3C-SiC layers were grown via LE mechanism using the sublimation epitaxial growth technique. ${ }^{10}$ The schematic illustration of the growth setup is shown in Figure 1.The materials 
are placed inside an inductively heated graphite crucible on top of each other in a sandwich-like arrangement with a tantalum foil at the bottom, followed by a polycrystalline $\mathrm{SiC}$ plate (source material), a graphite spacer with an opening for vapor species transport, a substrate and a graphite plate to prevent backside sublimation of the substrate. The tantalum foil acts as a carbon getter at elevated temperatures and leads to an increased concentration of silicon in the vapor phase inside the crucible. This is beneficial for the cubic polytype stabilization and expands the growth parameters window in which the graphitization of the source and substrate surfaces can be avoided. ${ }^{13,14}$ In all experiments, $4 \mathrm{H}-\mathrm{SiC}$ substrates with a 4 degree surface off-orientation from (0001) toward $<11-20>$ direction were used. Spacers with different types of opening shapes and thickness varying from 1 to $2 \mathrm{~mm}$ were explored. The growth temperatures were ranging from 1800 to $1950^{\circ} \mathrm{C}$ and growth times up to 10 hours were used.

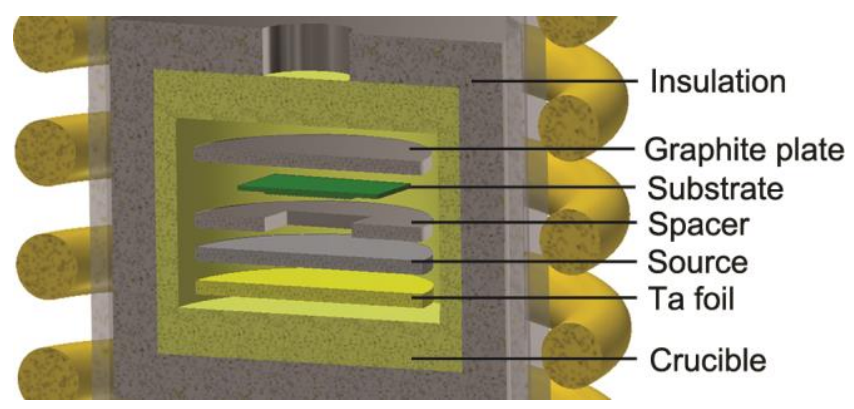

Figure 1. Schematic illustration of $3 \mathrm{C}-\mathrm{SiC}$ growth setup.

The surface morphology of the samples was investigated using an optical microscope with Nomarski interference contrast and scanning electron microscope (SEM). The crystalline quality was assessed by high resolution X-ray diffraction (HRXRD). The average values of the full width at half-maximum (FWHM) of $\omega$ rocking curves obtained on five different points on each samples using (111) Bragg reflection and a footprint of $1 \times 2.7 \mathrm{~mm}^{2}$ were used as indicators for 
the crystalline quality of $3 \mathrm{C}$-SiC layers. In addition, low temperature photoluminescence (LTPL) at a temperature of $2 \mathrm{~K}$ with the samples immersed in pumped liquid helium, using as an excitation the $351 \mathrm{~nm}$ line of an Ar-ion laser. The 3C-SiC layers were also analyzed using Raman spectroscopy using Jobin Yvon LabRAM HR-800 system with 633 nm He-Ne laser.

\section{RESULTS AND DISCUSSIONS}

The 3C-SiC layers grown using the LE mechanism pass through several interconnected growth stages. These include formation of a large terrace with an on-axis area at the edge of the sample, preferential nucleation of $3 \mathrm{C}-\mathrm{SiC}$ domains on the large terrace, and their lateral enlargement along the step-flow direction (Figure 2a). Therefore, the ultimate goal for obtaining high quality layer is the formation of a single domain $3 \mathrm{C}-\mathrm{SiC}$ on the large terrace. If such DPB-free domain is developed and its lateral enlargement pathway is free of obstacles or crystallographic defects, a single domain 3C-SiC layer can be grown.
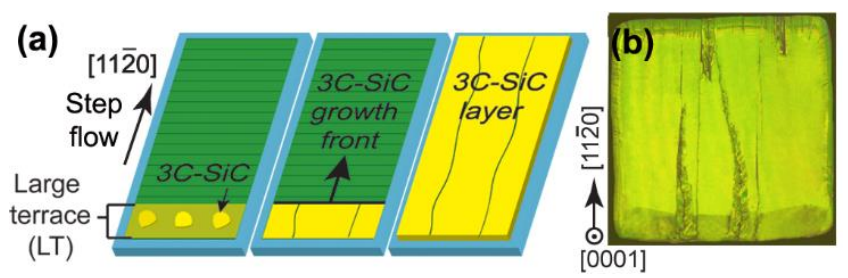

Figure 2. (a) Schematic illustration of 3C-SiC layer development, b) optical micrograph of a 3CSiC sample with a surface area of $7 \times 7 \mathrm{~mm}^{2}$.

Previously, the growth of 3C-SiC layers was demonstrated using the original LE growth arrangement that was based on a squared spacer opening. ${ }^{10}$ The layers grown using such 
arrangement still contain a few DPBs which propagate along the step-flow direction and leave several elongated surface defects in the resultant layer as seen in Figure $2 \mathrm{~b}$. To reduce and finally eliminate such defects, in the present work, we have: i) studied the formation mechanism of DPBs and other structural defects in thick (up to $1 \mathrm{~mm}$ ) 3C-SiC layers grown using different growth conditions, and ii) developed a two-step growth process which combined with geometrically controlled LE mechanism leads to growth of single domain 3C-SiC layers.

3.1 Structural defects analysis in thick 3C-SiC layers. In order to understand how we could further improve the structural quality of $3 \mathrm{C}-\mathrm{SiC}$ layers and optimize the LE mechanism in the original growth arrangement, we have conducted a study on samples grown using different growth rates, which in sublimation epitaxy are mainly governed by the growth temperature. ${ }^{15}$

The majority of DPBs in 3C-SiC layers grown via the LE mechanism originate at the edge of the sample during the initial formation of the $3 \mathrm{C}-\mathrm{SiC}$ and propagate along the step-flow direction as shown in Figure 3a. Additional 3C-SiC domains/inclusions may also occur in the central part of the layer. They are indicated as parasitic 3C-SiC (p-3C) in Figure 3a. The formation of p-3C can be induced by various crystallographic defects, mechanical damage or solid particles present on the surface of the $4 \mathrm{H}-\mathrm{SiC}$ substrate. They act as obstacles for propagating steps. Therefore, the step-flow is suppressed at the obstacle and a small on-axis area, that is a preferential 3C-SiC nucleation site, is created. If DPB propagating from the edge of the sample interact with $\mathrm{p}-3 \mathrm{C}$, the result is a cascade of multiple structural defects that propagate along the step-flow direction and deteriorate the epitaxial layer.

In general, the DPBs observed on about $1 \mathrm{~mm}$ thick $3 \mathrm{C}$-SiC layer surfaces can be categorized into "open" (V-shape) and "closed" (line-like) types as indicated in Figure 3b. On the surface the 
“open" type DPBs tend to broaden with an increase in layer thickness, while the "closed" type remains as line-like defect having a width which is almost independent of the layer thickness. This can be seen in cross sectional images taken from the stripes cut perpendicular to the stepflow direction at three different areas indicated as "A-A", "B-B" and "C-C" in Figure $3 \mathrm{~b}$. The "A-A" cut was done at the very edge of the layer where the large terrace with an on-axis area develops and the initial formation of $3 \mathrm{C}-\mathrm{SiC}$ domains takes place. A rough interface between the 3C-SiC and $4 \mathrm{H}-\mathrm{SiC}$ in the "A-A" cross sectional view indicates that there is a strong competition between these two polytypes during the initial growth stage.

(a)
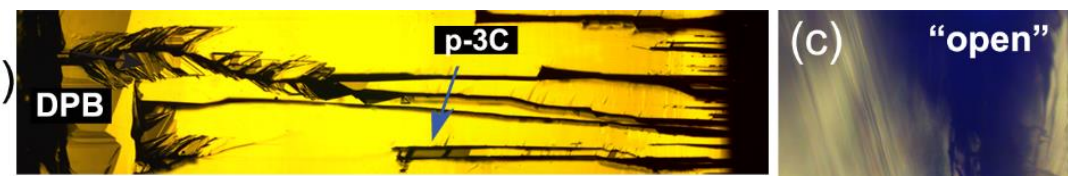

(b)
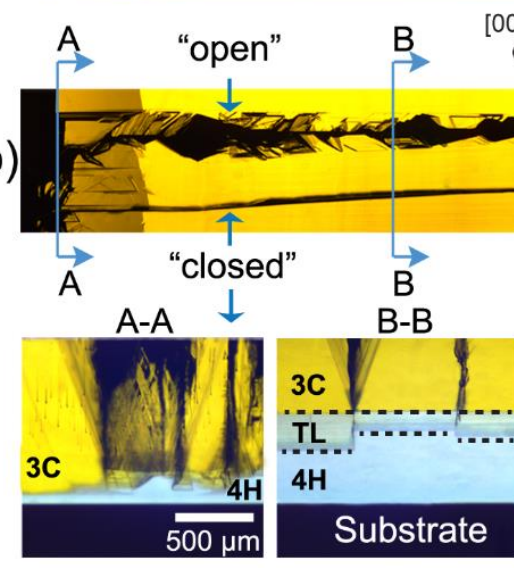

$\stackrel{[0001]}{\longrightarrow \rightarrow}[11 \overline{2} 0]$
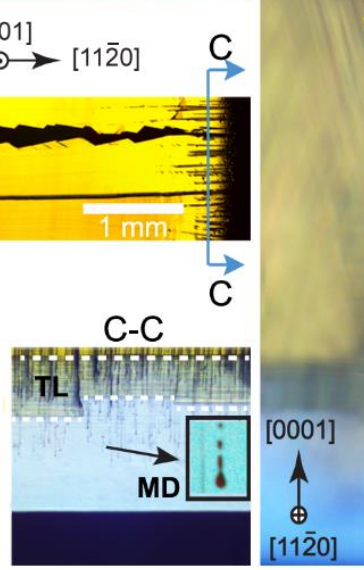

$[11 \overline{2} 0]$
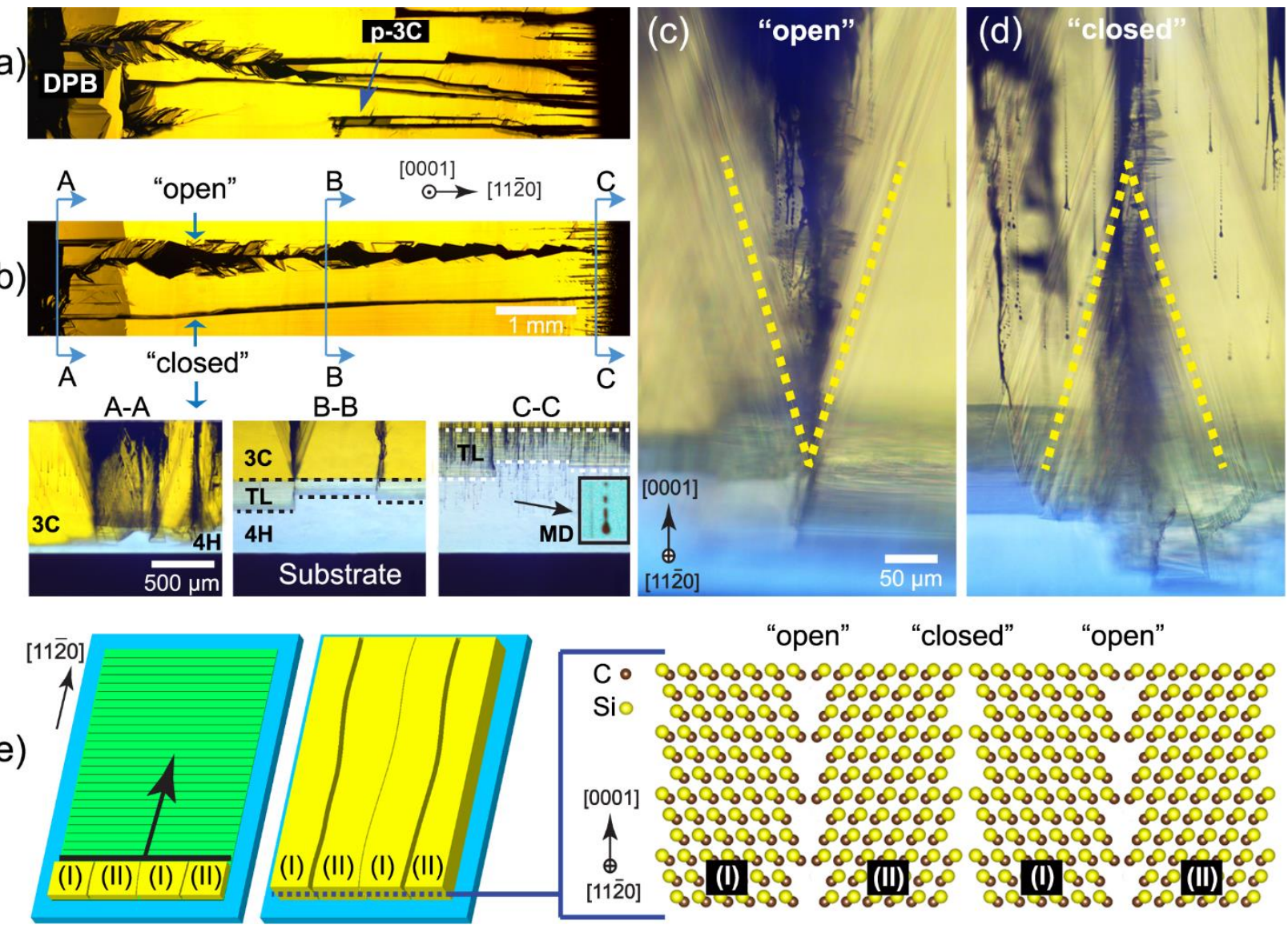

Figure 3. Optical micrographs: (a) surface of 3C-SiC layer with DPBs and parasitic 3C-SiC (p-

3C) inclusions, (b) cross sectional views of 3C-SiC layer, (c) enlarged view of "open" and (d) 
"closed" type DPBs. (e) Atomistic illustration of "open" and "closed" type DPBs formation during the initial growth stage.

In the cross sectional view of area "B-B" as shown in Figure 3b, the "open" (V-shape) and "closed" (line-like) type DPBs and the transition layer (indicated as "TL") between the 3C- and 4H-SiC are clearly visible. The change in the TL thickness is abrupt at points where DPBs are formed. There is a variation in TL thickness over the entire length of the $3 \mathrm{C}-\mathrm{SiC}$ layer. This is seen in the cross sectional view of "C-C" in Figure $3 \mathrm{~b}$ where the transition layer is thicker, but its profile observed in the cross sectional view of "B-B" is maintained.

The type of DPB ("open" or "closed") could be determined during the initial stage of 3C-SiC formation on the large terrace. This is clearly indicated in Figures 3c-d which show higher magnification cross sectional views of stripes that are cut perpendicular to the step-flow direction at the edge of the $3 \mathrm{C}-\mathrm{SiC}$ layer where the large terrace is formed. The DPBs are surrounded by line-fringes (dashed lines in Figure 3c-d as guide for the eye) which form either as open- or closed-V-shape defects. Such fringes are usually attributed to agglomeration of stacking faults or microtwins around incoherent twin boundaries. ${ }^{16}$ During the initial formation of $3 \mathrm{C}-\mathrm{SiC}$ on the large terrace, the 3C-SiC domains can nucleate in two equally possible orientations rotated by $60^{\circ}$ on (0001) plane due to two possible stacking orders of $\mathrm{ABCABC}$ and $\mathrm{ACBACB}$ along the [0001] direction. In Figure 3e such $60^{\circ}$-rotated domains are indicated as (I) and (II). Despite the rotation of domains, they have an enhanced lateral enlargement along the step-flow direction. At the same time they enlarge perpendicularly to the step-flow growth direction. Depending on the $3 \mathrm{C}-\mathrm{SiC}$ domains rotation and the side from which they approach each other in perpendicular to the step-flow direction the neighboring domains are inclined towards ("closed") or outwards 
("open”) with respect to each other along the c-axis as shown in Figure 3e. Therefore, if the DPBs are scanned perpendicular to the step-flow direction from one edge of the sample to the other edge, it can be observed that every second DPB originating from the very edge of the terrace possesses the same V-shape.

In order to understand further details of their formation, a series of 3C-SiC samples with $1 \mathrm{~mm}$ thickness were grown using different growth temperatures in the range from $1800^{\circ} \mathrm{C}$ to $1950^{\circ} \mathrm{C}$. As seen in Figure 4a the growth rate almost doubles if the growth temperature is increased by $50^{\circ} \mathrm{C}$. Therefore, the growth time needed to obtain $1 \mathrm{~mm}$ thick layer at $1800^{\circ} \mathrm{C}$ is about 10 hours while it is only about 1 hour at $1950^{\circ} \mathrm{C}$. The number of DPBs (counted using an optical microscope on the large terrace area) increases by increasing the growth temperature/growth rate (Figure $4 \mathrm{~b}$ ). The supersaturation increases with the increase in the growth temperature/growth rate and this leads to a higher density of $3 \mathrm{C}-\mathrm{SiC}$ nuclei and consequently higher density of DPBs which are formed on the large terrace. This indicates that lower growth temperatures/growth rates should be used for growth of high quality layers with minimized number of DPBs. However, there is a threshold in the growth rate below which the stability of the cubic polytype cannot be maintained. This was observed when $3 \mathrm{C}-\mathrm{SiC}$ layers were grown at a growth rate lower than $100 \mu \mathrm{m} / \mathrm{h}$. In this case, the $3 \mathrm{C}-\mathrm{SiC}$ that is formed at the edge of the sample contains foreign polytype inclusions which propagate along the step-flow direction. In addition, there is also an upper limit in the growth rate at which various structural defects start to appear to a substantially higher degree. For example, the $3 \mathrm{C}-\mathrm{SiC}$ layers grown at the temperature of $1950^{\circ} \mathrm{C}$ (corresponding to a growth rate of $\sim 1 \mathrm{~mm} / \mathrm{h}$ ) exhibit significantly higher density of parasitic $3 \mathrm{C}$ $\mathrm{SiC}$ inclusions in the center of the sample. 


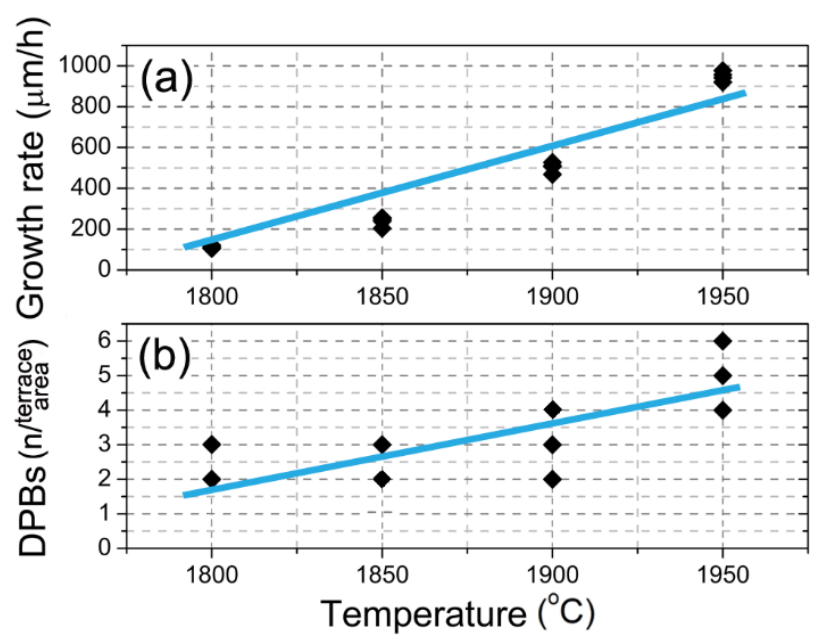

Figure 4. (a) Growth rate vs temperature, (b) number of DPBs per large terrace area vs growth temperature.

Another type of macro-defects which can be observed on the surface of the 3C-SiC layers are line-like defects. These are visible only at the very edge of the sample on the right side in Figure 3a and $b$. Such defects form via several development stages in which the transition layer plays an important role. A completely developed 3C-SiC layer may be viewed as a three-layer system, where there is a homoepitaxial $4 \mathrm{H}-\mathrm{SiC}$ layer at the bottom, which is followed by the transition layer and the 3C-SiC layer on the top. The transition layer enlarges laterally approximately two times faster than the $3 \mathrm{C}$-SiC layer. ${ }^{10}$ The growth front of the transition layer contains a rough surface with an elongated groove-like pattern. This is shown in the SEM micrograph in Figure 5a which was obtained from the surface of a sample with low 3C-SiC coverage and a total layer thickness of $250 \mu \mathrm{m}$. The groove-like pattern becomes more pronounced when the transition layer propagates along the step-flow growth direction and approaches the opposite edge that is shown in Figure 5b. Moreover, the groove-like pattern is accompanied by extended defects (ED in Figure 5b). The origin of these defects is threading defects (indicated as "MD" in the cross 
section view of "C-C" in Figure 3b) which are propagating in the $4 \mathrm{H}-\mathrm{SiC}$ homoepitaxial layer. Due to the pronounced groove-like pattern at the edge, the part of 3C-SiC which contains the most defects is also located at this edge. The density of these extended defects varies from sample to sample and does not correlate clearly with the growth parameters. Therefore, other factors like microscopic defects in the substrate or built-up stress between the homoepitaxial and transition layers could be causing the formation of such defects. 

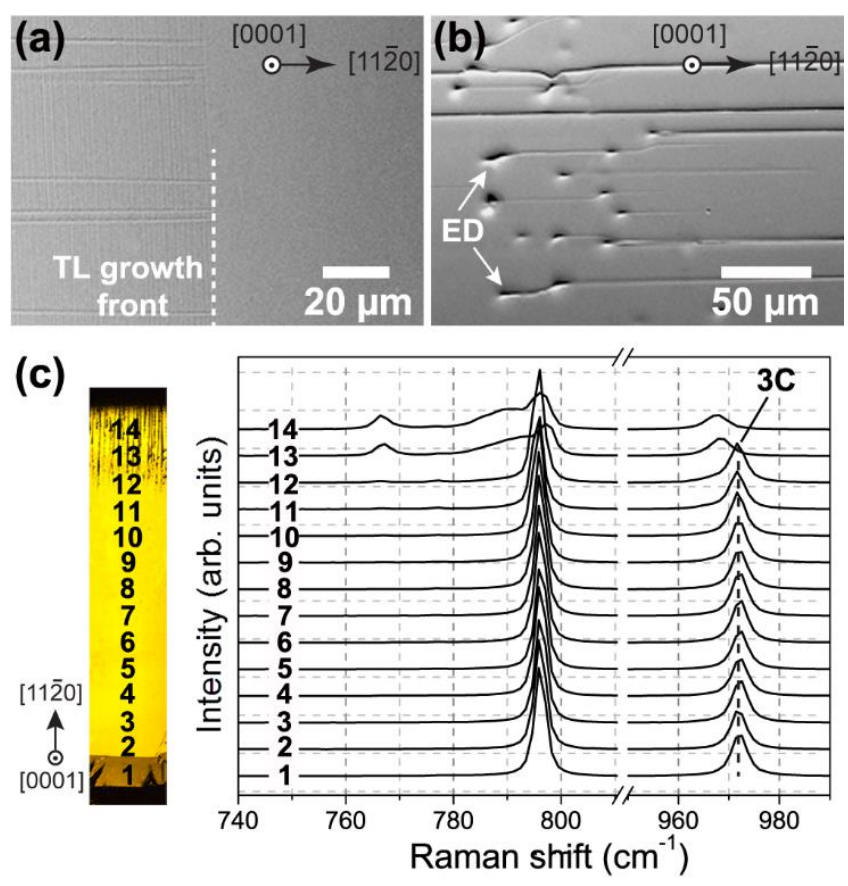

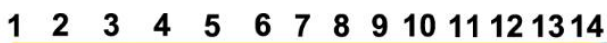
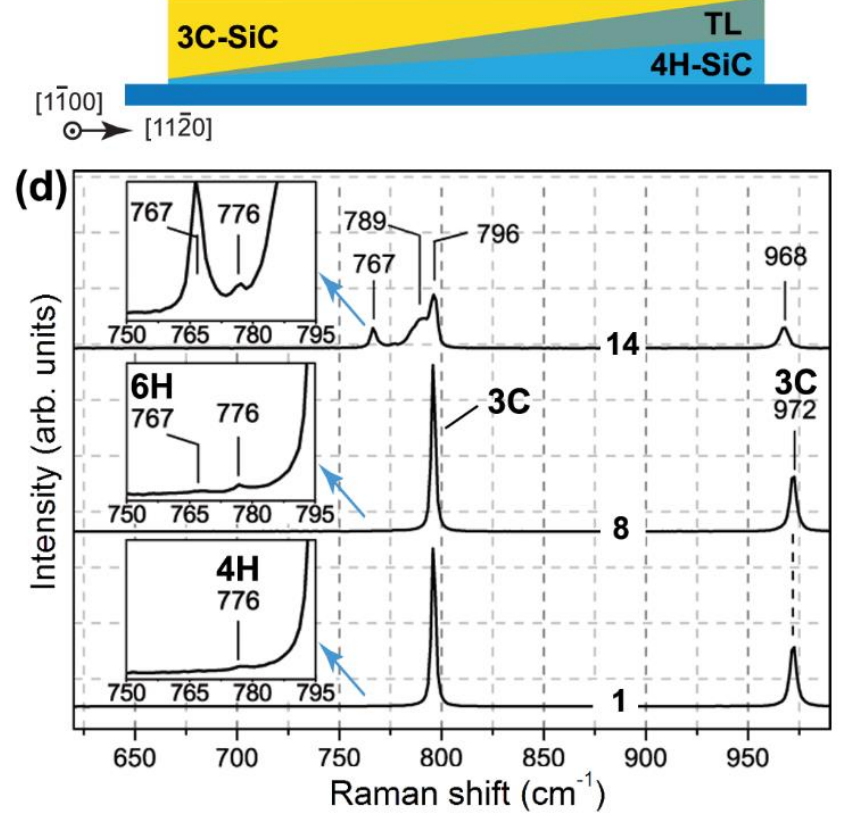

Figure 5. SEM micrographs of (a) transition layer growth front (total layer thickness $\sim 250 \mu \mathrm{m}$ ), (b) extended defects (ED) (total layer thickness $\sim 1 \mathrm{~mm}$ ). (c) Raman spectra measured on different positions along the step-flow direction in $3 \mathrm{C}-\mathrm{SiC}$ layer (thickness $\sim 900 \mu \mathrm{m}$ ), (d) enlarged view of the Raman spectra obtained on points 1,8 and 14. 
Micro-Raman spectroscopy in the back scattering geometry was used to scan a 3C-SiC layer (thickness $\sim 900 \mu \mathrm{m}$ ) that contains extended defects as shown in Figure 5b. As seen in Figure 5c, the Raman spectra change significantly when scanning the layer along the step-flow direction (from point 1 to point 14). In Figure 5d a more detailed view of the Raman peaks obtained from three measurement points $(1,8$, and 14) is presented. The inset above the Raman spectrum of point 1 shows a small peak at $776 \mathrm{~cm}^{-1}$ which corresponds to the folded transverse optical (FTO) mode of $4 \mathrm{H}-\mathrm{SiC}^{17}$ and is therefore attributed to contribution from the substrate. Its appearance is expected in view of the fact that both $3 \mathrm{C}$ - and $4 \mathrm{H}-\mathrm{SiC}$ are transparent for the exciting $633 \mathrm{~nm}$ laser beam, ${ }^{18}$ and its gradual intensity increase from point 1 to point 14 is in line with the decreasing 3C-SiC layer thickness. The line observed at $767 \mathrm{~cm}^{-1}$ for points 8 and 14 corresponds to the FTO of $6 \mathrm{H}-\mathrm{SiC}$. This line also gets stronger when moving the laser beam from point 1 to 14 along the step-flow direction and is most likely due to the transition layer which is buried under the $3 \mathrm{C}-\mathrm{SiC}$ layer but approaches the sample surface in the thinnest part (point 14).

The FLO mode of 3C-SiC at $972 \mathrm{~cm}^{-1}$ remains at the same position for all spectra measured at points 1-12. This indicates that at these points the surface of the layer is fully covered with $3 \mathrm{C}$ SiC. A significant change in the Raman spectra is observed at the opposite edge of the sample where the $3 \mathrm{C}-\mathrm{SiC}$ layer is thin. This location contains extended defects and the transition layer is the thickest. A strong FTO mode of $6 \mathrm{H}-\mathrm{SiC}$ at $767 \mathrm{~cm}^{-1}$ is seen in the spectra measured at points 13 and 14. The FLO peak of 3C-SiC, which remains un-shifted at $972 \mathrm{~cm}^{-1}$ for points $1-12$, downshifts to $967-968 \mathrm{~cm}^{-1}$ for points 13 and 14 . This indicates that the Raman spectrum becomes dominated by other polytypes from the transition layer. Also, a broader line peaking 
around $789 \mathrm{~cm}^{-1}$ can be observed at points 13 and 14, which most probably originates from an overlap of the FTO modes of a mixture of polytypes present in the transition layer (e.g., 21R-, $6 \mathrm{H}-$ and $15 \mathrm{R}-\mathrm{SiC}$ at 791,789 and $785 \mathrm{~cm}^{-1}$, respectively). ${ }^{17}$

While DPBs are the most prominent, the next most important defects in 3C-SiC are stacking faults (SFs). The 3C-SiC has the lowest SFs formation energy, which varies from -1.71 to -6.27 $\mathrm{mJ} / \mathrm{m}^{2}$ compared to 3.1 to $40.1 \mathrm{~mJ} / \mathrm{m}^{2}$ in $6 \mathrm{H}-\mathrm{SiC}$ and 17.7 to $18.7 \mathrm{~mJ} / \mathrm{m}^{2}$ in $4 \mathrm{H}-\mathrm{SiC} .{ }^{19} \mathrm{It}$ has been demonstrated that the density of SFs can be reduced in 3C-SiC grown on patterned $\mathrm{Si}$ substrates. ${ }^{20,21}$ Small SF-free 3C-SiC areas can be grown on a step-free $4 \mathrm{H}-\mathrm{SiC}$ mesas. ${ }^{22}$ However, to our knowledge there is no data on large-area SF-free 3C-SiC layers.

Molten potassium hydroxide $(\mathrm{KOH})$ was used to reveal stacking faults in $3 \mathrm{C}-\mathrm{SiC}$ layers grown at three different temperatures/growth rates. Stripes along the step-flow direction were cut from a single domain area and etched in molten $\mathrm{KOH}$ at $500^{\circ} \mathrm{C}$ for $1 \mathrm{~min}$. In such a way SFs on two perpendicular surfaces, which corresponds to hexagonal (0001) and (1-100) planes, were revealed in a single sample. On the (0001) surface, which corresponds to (111) in the $3 \mathrm{C}-\mathrm{SiC}$ layer, the SFs occur as lines which are forming one or more sides of equilateral triangles whose density depends mainly on the thickness of the $3 \mathrm{C}-\mathrm{SiC}$ layer rather than on growth parameters (Figure 6a-c). The highest density of triangular features is observed on the right side (which corresponds to the thinnest part of the $3 \mathrm{C}$-SiC layer) of each stripe and gradually decreases with an increase in the layer thickness. This reflects that the highest number of stacking faults is formed at the transition layer $/ 3 \mathrm{C}-\mathrm{SiC}$ interface. It is likely that there is a mismatch caused by the $3 \mathrm{C}-\mathrm{SiC}$ and the transition layer. The relief of mismatch strain results in formation of stacking faults. The same thickness dependent density trend of triangular features was observed on etched (1-100) surfaces. A representative picture of such etched 3C-SiC surface is shown in Figure 6d. 
The decrease of stacking fault density with the increase in layer thickness suggests that the growth of bulk 3C-SiC could be a way to further reduce stacking faults.
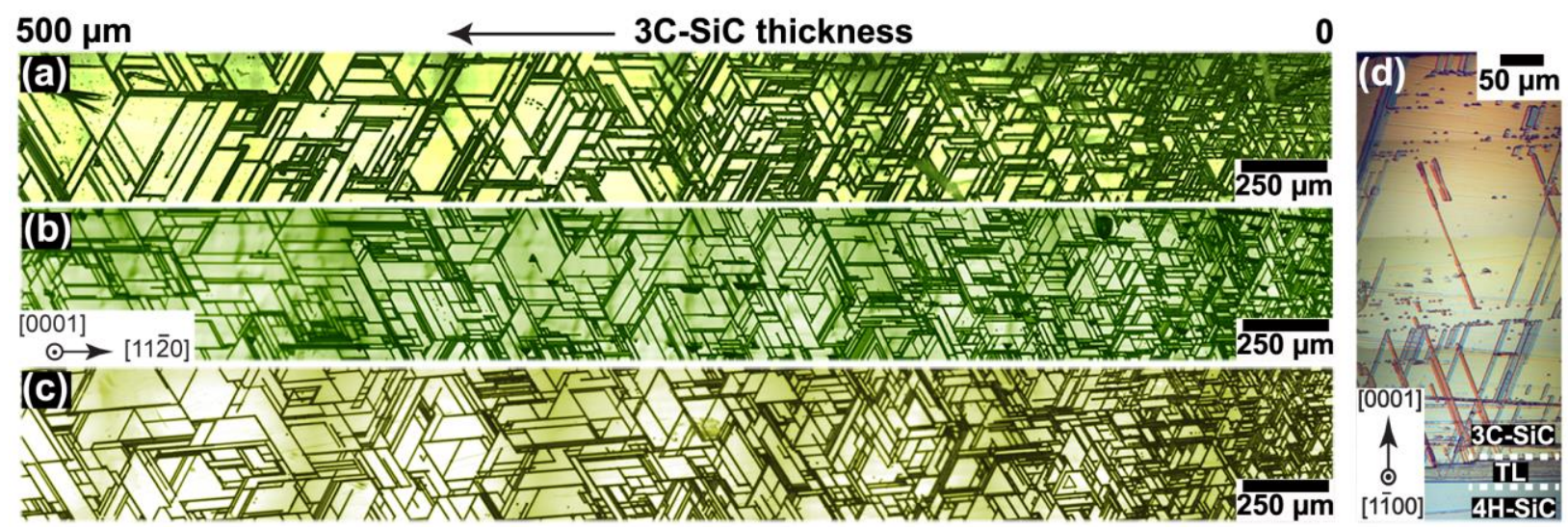

Figure 6. Optical micrograph of $\mathrm{KOH}$ etched 3C-SiC (111) surfaces, which correspond to hexagonal (0001), grown at (a) $1800^{\circ} \mathrm{C}$, (b) $1850^{\circ} \mathrm{C}$ and (c) $1900^{\circ} \mathrm{C}$, (d) optical micrograph of $\mathrm{KOH}$ etched $3 \mathrm{C}-\mathrm{SiC}$ surface grown at $1850^{\circ} \mathrm{C}$ which corresponds to hexagonal (1-100).

3.2 Two-step process. As demonstrated in the analysis of defects in the previous section, the formation of DPBs can be controlled by changing growth parameters, while the density of triangular features, which are imprints of SFs in 3C-SiC (111), depends mainly on the layer thickness. The formation of other crystallographic defects can be correlated with the quality of the substrate surface. Based on the study shown in Figure 4, the 3C-SiC layers should be grown at $1800^{\circ} \mathrm{C}$ which in our sublimation growth setup has a growth rate of about $100 \mu \mathrm{m} / \mathrm{h}$ and resulted in a low number of DPBs formed on the large terrace. However, at such growth rate the growth time needed to obtain a layer with a thickness of $1 \mathrm{~mm}$ is 10 hours. In order to demonstrate thick 3C-SiC growth at an industrially attractive growth rate, a two-step growth process was introduced. A detailed breakdown of the growth process is presented in Figure 7. 


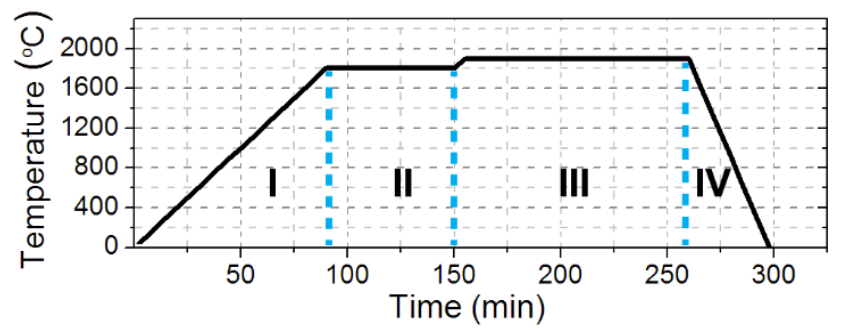

Figure 7. Two-step growth process of $3 \mathrm{C}-\mathrm{SiC}$ layers with a temperature ramp up and ramp down steps.

The area indicated as "I" (Figure 7) corresponds to the temperature ramp up at a rate of 20 ${ }^{\circ} \mathrm{C} / \mathrm{min}$ up to the growth temperature of $1800^{\circ} \mathrm{C}$. This growth temperature was maintained for 1 hour and during this time (area marked as "II" in Figure 7), a 3C-SiC growth front with a low $\mathrm{DPB}$ density is formed. After that, the temperature is increased to $1900^{\circ} \mathrm{C}$ and maintained for 1 hour and 45 min ("III" in Figure 7). During this step, the growth rate increases from $\sim 100 \mu \mathrm{m} / \mathrm{h}$ to $\sim 500 \mu \mathrm{m} / \mathrm{h}$, which corresponds to $3 \mathrm{C}-\mathrm{SiC}$ lateral enlargement rate of $\sim 3.5 \mathrm{~mm} / \mathrm{h}$. After the growth is completed, the induction heating is switched off and the layer is cooled down (Figure 7 "IV"). The quality, in terms of DPBs, of 3C-SiC layers grown using such two-step process, is very similar to the layers grown at $1800^{\circ} \mathrm{C}$, while the time (excluding temperature ramp-up and cooling down) is reduced from 10 hours to 2 hours $45 \mathrm{~min}$.

3.3 Geometrically controlled lateral enlargement. It has been demonstrated that the control of 3C-SiC nucleation using CVD growth over a small area can be obtained by patterning the surface of a $4 \mathrm{H}-\mathrm{SiC}$ substrate using photolithography to form mesas in different geometries. ${ }^{23,24}$ Initial results of the effect of the graphite spacer opening shape in 3C-SiC nucleation using 
sublimation epitaxy on low off-axis $6 \mathrm{H}-\mathrm{SiC}$ substrates have been also shown. ${ }^{25}$ Here we explore a geometrical control and demonstrate that different spacer shaping can be applied to promote formation of only one 3C-SiC domain that enlarges and completely covers the surface of the epilayer.

In the original $3 \mathrm{C}-\mathrm{SiC}$ lateral enlargement growth setup, the substrate is placed on the spacer in such a way that the step-flow direction is perpendicular to the edge of the spacer opening as shown in Figure 8a. In this case, the initial 3C-SiC domains form on the large terrace with an onaxis surface along the edge of the layer. Ideally, only one nucleation center/domain of $3 \mathrm{C}-\mathrm{SiC}$ on the terrace would form. However, several 3C-SiC domains always form due to the large surface area of the terrace. In order to avoid this, two conditions are required: i) the growth parameters should be adjusted to form a minimum number of $3 \mathrm{C}-\mathrm{SiC}$ domains on the terrace during the initial growth, and ii) the area on which $3 \mathrm{C}-\mathrm{SiC}$ domains form should be minimal to facilitate single-domain formation. The first condition can be met by using two-step process which allows to reduce the number of $3 \mathrm{C}-\mathrm{SiC}$ domains while the second condition prompts for changes in the geometrical arrangement in the growth cell, namely, in the shape of the opening in the spacer.

In our growth concept a terrace with an on-axis surface preferentially forms along the edge of the spacer opening which is perpendicular to the step-flow direction as shown in Figure 8a. In order to reduce the surface area of the terrace, two other shapes of the spacer opening were explored. The first one is the same squared opening as the original one, but rotated by 45 degrees (Figure $8 b$ ) with respect to the [11-20] direction. The idea for using such spacer is to form a small on-axis area at the corner of the substrate at which the nucleation begins. The second opening has a circular shape (Figure 8c). In this case, the size of the terrace is larger than the one given by the 45 degree rotation opening, but smaller than in the original one. 
The comparative results are shown in Figure 8d-f. The growth times were adjusted to have a layer thickness of $1.2 \mathrm{~mm}$ using the original (Figure 8a) and circular (Figure 8c) spacer openings, and $1.4 \mathrm{~mm}$ using the $45 \mathrm{deg}$ rotated spacer (Figure $8 \mathrm{~b}$ ). In the latter case a larger thickness is needed to ensure a complete surface coverage with 3C-SiC due to the longer distance the 3C-SiC domain needs to travel along the diagonal of the square. The 3C-SiC samples shown in Figure 8d-f are free-standing layers obtained by polishing away the 4H-SiC substrate.

(a)

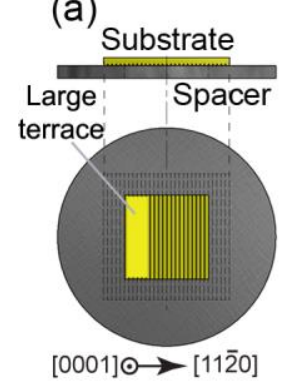

(d)

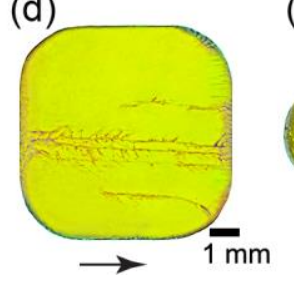

(b)

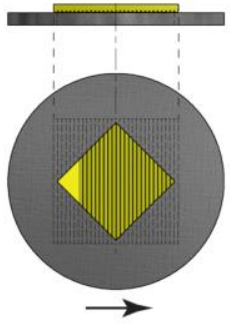

(e)

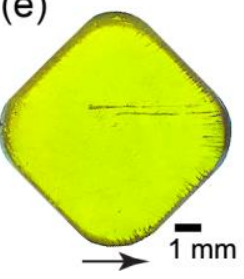

(c)

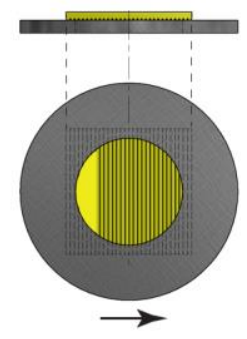

(f)

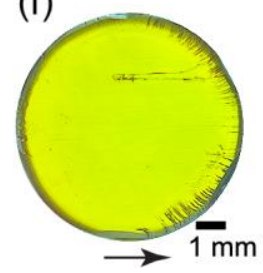

Figure 8. (a-c) Schematic illustration of spacer and substrate arrangements. Optical micrographs of the freestanding 3C-SiC grown using (d) original (e), 45 degree rotated and (f) circular spacer openings. Black arrows indicate step-flow growth direction.

Clearly, the number of domains is substantially decreased in both non-original arrangements. In fact, we have obtained a single domain growth. However, parasitic 3C-SiC inclusions, seen as lines in the center of samples in Figure 8e-f, may still form on the surface. Similarly to homoepitaxial growth in high growth rate epitaxy on $6 \mathrm{H}$ and $4 \mathrm{H}-\mathrm{SiC}^{15}$, we believe they are 
originating from the defects in the substrate or are caused by residual contaminants on the substrate surface after the chemical cleaning process.

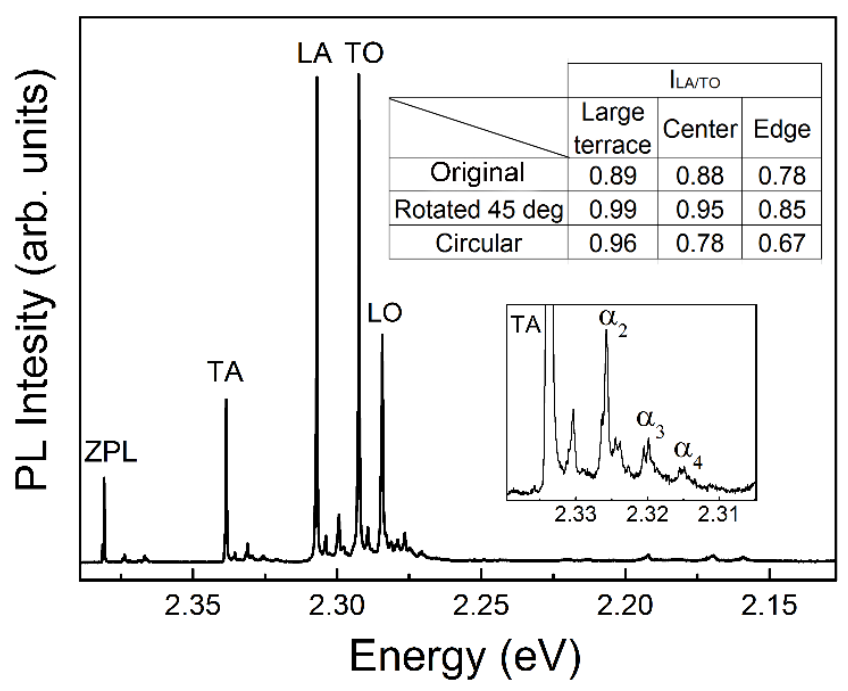

Figure 9. LTPL spectrum of $3 \mathrm{C}-\mathrm{SiC}$. The inset shows $\mathrm{I}_{\mathrm{LA}} /$ To ratios measured on three different areas on each sample shown in Figure 7d-f. The "Large terrace" area represents the thickest and the "Edge" the thinnest part of the 3C-SiC layer on the sample.

In order to investigate if the shape of the layer induces any changes in the 3C-SiC material quality we carried out LTPL measurements at $2 \mathrm{~K}$. Three spectra from three locations were obtained for each sample: i) at the edge where the large terrace is formed and $3 \mathrm{C}$-SiC has largest thickness, ii) in the center of the sample and iii) at the opposite edge with the thinnest part of $3 \mathrm{C}$ $\mathrm{SiC}$ layer. Due to the low penetration depth of the exciting laser $(351 \mathrm{~nm})$ no contribution from other $\mathrm{SiC}$ polytypes but $3 \mathrm{C}$-SiC could be detected in the spectra. Each spectrum demonstrates well resolved near-band-edge features and lines associated with multiple bound-exciton complexes with up to four electron-hole pairs indicating high quality of $3 \mathrm{C}-\mathrm{SiC}$ material. ${ }^{26,27} \mathrm{~A}$ spectrum representative for all samples is displayed in Figure 9. Nitrogen concentration of 6- 
$8 \times 10^{15} \mathrm{~cm}^{-3}$ was estimated in all samples using the FWHM of the TA-phonon replica. ${ }^{28}$ Moreover, we have observed that the biaxial stress, which can be estimated using the $\mathrm{I}_{\mathrm{LA}} / \mathrm{I}_{\mathrm{TO}}$ intensity ratio, ${ }^{29}$ varies along the step-flow direction in each sample as presented in the inset table in Figure 9. The ILA $/ \mathrm{I}_{\text {Tо }}$ ratio shows a clear dependence of biaxial stress on the thickness of the $3 \mathrm{C}-\mathrm{SiC}$ and approaches a value of one (which reflects that biaxial stress more or less vanishes) when the thickness of the $3 \mathrm{C}-\mathrm{SiC}$ layer is about $1.2 \mathrm{~mm}$. Based on $\mathrm{I}_{\mathrm{LA}} / \mathrm{I}_{\mathrm{TO}}$ values presented in the inset table, we cannot distinguish if any of the shapes induces higher or lower overall biaxial stress than the others. For instance, the original and circular 3C-SiC layers have similar total thicknesses. However, there can be some thickness variations leading to different $\mathrm{I}_{\mathrm{LA}} / \mathrm{I}_{\mathrm{TO}}$ values, when measuring, for example, at the "center" location in both $3 \mathrm{C}-\mathrm{SiC}$ layers. Nevertheless, we can conclude that all three samples possess very similar crystalline quality which is also confirmed by HRXRD in the next section.

3.4 Comparison of different 3C-SiC growth schemes. The experimental work presented in previous sections allowed us to explore the formation of various structural defects and propose growth schemes for the improvement of the original LE mechanism. In Table 1, we present a summary of different growth schemes. As demonstrated in our previous study, the $3 \mathrm{C}$-SiC layers grown using the original LE mechanism show state of the art quality compared to 3C-SiC grown on silicon or hexagonal silicon carbide substrates. ${ }^{10}$ However, the original LE mechanism (growth rate $\sim 0.5 \mathrm{~mm} / \mathrm{h}$ ) cannot realize growth of single domain 3C-SiC layers due to a multiple 3C-SiC domains formation on the large terrace. A single 3C-SiC domain on the terrace area was achieved only by combining the two-step process with a geometrically controlled LE mechanism at an average growth rate of $\sim 0.36 \mathrm{~mm} / \mathrm{h}$. While we managed to control DPBs on the terrace 
area, elimination of other structural defects needs additional studies. We have observed that the density of triangular defects (imprints of the SFs) revealed by $\mathrm{KOH}$ etching is rather thicknessthan processdependent in all growth schemes. Parasitic 3C-SiC (p-3C) inclusion nucleation in the center of the sample is mainly determined by the substrate surface quality. This is also an issue in formation of defects (ED and $\mathrm{MD}$ ) at the edge opposite to the large terrace. Nevertheless, the combination of the two-step process and a geometrically controlled lateral enlargement mechanism allows production of single domain 3C-SiC layers which can be explored in homoepitaxy for devices or as seeds for the bulk growth of 3C-SiC crystals.

Table 1. Summary of different $3 \mathrm{C}-\mathrm{SiC}$ growth schemes and material characteristics.

\begin{tabular}{|l|l|l|l|}
\hline & $\begin{array}{l}\text { original LE } \\
\text { mechanism }\end{array}$ & \multicolumn{2}{|l|}{ two-step process + geometrical control } \\
\hline spacer opening & $\begin{array}{l}\text { original (squared } \\
\left.7 \times 7 \mathrm{~mm}^{2}\right)\end{array}$ & $\begin{array}{l}45 \text { deg rotated } \\
\left(\text { squared }-7 \times 7 \mathrm{~mm}^{2}\right.\end{array}$ & $\begin{array}{l}\text { circular (diameter }-7 \\
\mathrm{~mm})\end{array}$ \\
\hline $\begin{array}{l}\text { avg. growth rate } \\
(\mu \mathrm{m} / \mathrm{h})\end{array}$ & $\sim 500$ & $\sim 360$ & $\sim 360$ \\
\hline DPBs/terrace area & up to 4 & 0 & 0 \\
\hline $\begin{array}{l}\text { SFs revealed by } \\
\text { KOH etching }\end{array}$ & $3 \mathrm{C}$-SiC layer thickness dependent \\
\hline p-3Cs per sample & substrate surface quality related \\
\hline $\begin{array}{l}\text { MDs and EDs at the } \\
\text { edge of sample }\end{array}$ & substrate quality and 3C-SiC sample structure related \\
\hline $\begin{array}{l}\text { HRXRD (avg. fwhm } \\
(\text { arcsec) })\end{array}$ & 40 & \multicolumn{3}{|l|}{38} \\
\hline LTPL & $\begin{array}{l}100 \% \text { surface coverage with 3C-SiC and multiple bound-exciton } \\
\text { complexes with up to four electron-hole pairs in all layers }\end{array}$ \\
\hline
\end{tabular}




\section{CONCLUSIONS}

Growth of single domain 3C-SiC layers was achieved by a combination of different growth schemes. These schemes were developed by studying structural defects in thick ( up to $1 \mathrm{~mm})$ 3C-SiC layers grown using different growth conditions via an original lateral enlargement mechanism. We have observed that the density of DPBs can be reduced by lowering the growth rate, while SFs density mainly depends on the layer thickness. Furthermore, we have explained the formation of extended defects which are observed at the very edge on the surface of $3 \mathrm{C}-\mathrm{SiC}$ layers. On the basis of the results of structural defects formation in thick 3C-SiC grown using different growth conditions, we have developed a two-step process that allows reduction of DPBs on the large terrace. A complete elimination of DPBs on the large terrace or formation of only one $3 \mathrm{C}-\mathrm{SiC}$ domain that enlarges and covers the complete surface was achieved by combining the two-step process with the geometrically controlled lateral enlargement mechanism. In this way, single domain $3 \mathrm{C}$-SiC layers with a squared $(7 \times 7 \mathrm{~mm} 2)$ or circular shape (diameter $7 \mathrm{~mm}$ ) and a total layer thickness up to $1.4 \mathrm{~mm}$ were obtained. As demonstrated by HRXRD (average value of fwhm of $\omega$ rocking curves is 38 arcsec) and LTPL measurement data, the layers possess high crystalline quality. 


\section{AUTHOR INFORMATION}

\section{Corresponding Author}

*valjo@ifm.liu.se

\section{Funding Sources}

The Swedish Energy Agency, Swedish Research Council and the Swedish Governmental Agency for Innovation Systems (Vinnova).

\section{REFERENCES}

[1]Kato, M.; Yasuda, T.; Miyake, K.; Ichimura, M.; Hatayama, T. Int J Hydrogen Energy 2014,39, 4845-4849.

[2]Saddow, S. E.; Frewin, C. L.; Coletti, C.; Schettini, N.; Weeber, E.; Oliveros, A.; Jarosezski, M. Mater. Sci. Forum 2011,679 - 680, 824.

[3]Beaucarne, G.; Brown, A. S.; Keevers, M. J.; Corkish, R.; Green, M. A. Prog Photovoltaics Res Appl 2002,10, 345-353.

[4]Schöner, A.; Krieger, M.; Pensl, G.; Abe, M.; Nagasawa, H. Chem. Vapor Depos. 2006,12, 523-530.

[5]Powell, J. A.; Neudeck, P. G.; Trunek, A. J.; Beheim, G. M.; Matus, L. G.; Hoffman, R. W.; Keys, L. J. Appl. Phys. Lett. 2000,77, 1449-1451.

[6]Soueidan, M.; Ferro, G. Adv. Funct. Mater. 2006,16, 975-979. 
[7]Chaussende, D.; Latu-Romain, L.; Auvray, L.; Ucar, M.; Pons, M.; Madar, M. Mater. Sci. Forum 2005,483, 225.

[8]Leone, S.; Beyer, F. C.; Henry, A.; Kordina, O.; Janzén, E. Phys. Status Solidi (RRL) 2010,4, 305-307.

[9]Lebedev, A. A.; Abramov, P. L.; Zubrilov, A.; Bogdanova, E. V.; Lebedev, S. P.; Seredova, N. V.; Tregubova, A. S. Mater. Sci. Forum 2011,679, 12-15.

[10]Jokubavicius, V.; Yazdi, G. R.; Liljedahl, R.; Ivanov, I. G.; Yakimova, R.; Syväjärvi, M. Cryst. Growth Des. 2014,14, 6514-6520.

[11]Kohyama, M.; Yamamoto, R. Solid State Phenomena 1994,37, 55.

[12]Vasiliauskas, R.; Mekys, A.; Malinovskis, P.; Syväjärvi, M.; Storasta, J.; Yakimova, R. Mater. Lett. 2012,74, 203-205.

[13]Vodakov, Y. A.; Roenkov, A. D.; Ramm, M. G.; Mokhov, E. N.; Makarov, Y. N. Phys. Status Solidi B 1997,202, 177-200.

[14]Karpov, S. Y.; Makarov, Y. N.; Ramm, M. S. Phys. Status Solidi B 1997,202, 201-220.

[15]Syväjärvi, M.; Yakimova, R.; Tuominen, M.; Kakanakova-Georgieva, A.; MacMillan, M. F.; Henry, A.; Wahab, Q.; Janzén, E. J. Cryst. Growth 1999,197, 155-162.

[16]Ferro, G.; Kim-Hak, O.; Lorenzzi, J.; Jegenyes, N.; Marinova, M.; Soueidan, M.; Carole, D.; Polychroniadis, E. K. Mater. Sci. Forum 2011,679, 71-74. 
[17]Nakashima, S.; Harima, H. Phys. Status Solidi A 1997,162, 39-64.

[18]Harima, H. Microelectron. Eng. 2006,83, 126-129.

[19]Lindefelt, U.; Iwata, H.; Oberg, S.; Briddon, P. R. Phys.Rev.B 2003,67, 155204.

[20]D'Arrigo, G.; Severino, A.; Milazzo, G.; Bongiorno, C.; Piluso, N.; Abbondanza, G.;

Mauceri, M.; Condorelli, G.; La Via, F. Mater. Sci. Forum 2010,645, 135-138.

[21]Nagasawa, H.; Yagi, K.; Kawahara, T. J. Cryst. Growth 2002,237, 1244-1249.

[22]Speer, K.; Neudeck, P.; Spry, D.; Trunek, A.; Pirouz, P. J. Electron. Mater. 2008,37, 672680.

[23]Lorenzzi, J.; Lazar, M.; Tournier, D.; Jegenyes, N.; Carole, D.; Cauwet, F.; Ferro, G. Cryst. Growth Des. 2011,11, 2177-2182.

[24]Neudeck, P. G.; Trunek, A. J.; Spry, D. J.; Powell, J. A.; Du, H.; Skowronski, M.; Huang, X. R.; Dudley, M. Chem. Vapor Depos. 2006,12, 531-540.

[25]Jokubavicius, V.; Liljedahl, R.; Ou, Y. Y.; Ou, H. Y.; Kamiyama, S.; Yakimova, R.; Syväjärvi, M. Mater. Sci. Forum 2011,679, 103-106.

[26]Bergman, J. P.; Janzén, E.; Choyke, W. J. Phys. Status Solidi B 1998,210, 407-413.

[27]Latu-Romain, L.; Chaussende, D.; Balloud, C.; Juillaguet, S.; Rapenne, L.; Pernot, E.; Camassel, J.; Pons, M.; Madar, M. Mater. Sci. Forum 2006,527, 99. 
[28]Camassel, J.; Juillaguet, S.; Zielinski, M.; Balloud, C. Chem. Vapor Depos. 2006,12, 549-

556.

[29]Choyke, W. J.; Feng, Z. C.; Powell, J. A. J. Appl. Phys. 1988,64, 3163-3175.

For Table of Contents Use Only

\section{Single domain 3C-SiC growth on off-oriented $4 \mathrm{H}-\mathrm{SiC}$ substrates}

Valdas Jokubavicius*, ${ }^{\text {, }}$, G. Reza Yazdi ${ }^{1}$, Rickard Liljedah ${ }^{1}$, Ivan G. Ivanov ${ }^{1}$, Jianwu Sun ${ }^{1}$, Xinyu Liu ${ }^{1}$, Philipp Schuh², Martin Wilhelm², Peter Wellmann², Rositsa Yakimova ${ }^{1}$, Mikael Syväjärvi ${ }^{1}$

${ }^{1}$ Department of Physics, Chemistry and Biology (IFM), Semiconductor Materials Division, Linköping University, 58183 Linköping, Sweden

${ }^{2}$ Materials Department 6 (i-meet), Crystal Growth Lab, University of Erlangen, Martens Straße 7, D91058 Erlangen, Germany
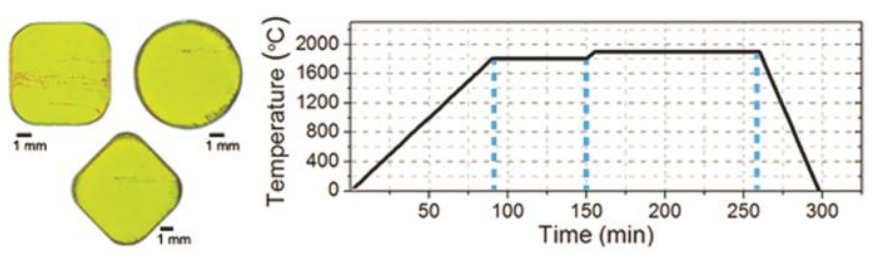

A combination of a two-step process and geometrically controlled lateral enlargement mechanism allows to form a single $3 \mathrm{C}$-SiC domain which enlarges and completely covers the surface of the substrate. High quality 3C-SiC layers with the thickness up to $1.4 \mathrm{~mm}$ have been demonstrated. 